Vol. 4, No. 2, Desember 2019, pISSN 2527-2853, eISSN 2549-2985

\title{
Desain Interior Museum Modern and Contemporary Art in Nusantara, Konsep Global Metropolitan Culture
}

\author{
Tunjung Atmadi ${ }^{1}$, Kiki Nurmallah ${ }^{2}$ \\ 1,2 Program Studi Desain Interior, Universitas Mercu Buana \\ tunjung.atmadi@mercubuana.ac.id ${ }^{1}$, knurmallah@gmail.com²
}

\begin{abstract}
ABSTRAK
Ditengah modernisasi seperti dewasa ini keberadaan museum mulai terabaikan. Dengan adanya Museum Modern and Contemporary Art in Nusantara yang merupakan institusi seni berbasis di Jakarta yang menjadi pertama dalam jenisnya. Museum ini adalah yang pertama untuk memberikan akses publik terhadap koleksi seni modern dan kontemporer yang berasal dari Indonesia dan internasional. Memiliki program pameran dan acara aktif di fasilitas seluas 7.100 meter persegi termasuk pendidikan di tempat dan ruang konservasi. Museum adalah sebuah lembaga yang tetap untuk kepentingan masyarakat dan perkembangannya serta terbuka untuk umum dengan tujuan edukatif maupun rekreatif. Maka dari itu desain sebuah interior museum perlu diperhatikan demi mendukung kesuksesan sebuah desain museum antara lain dalam hal teknik display, pengkategorian galeri, system signage, maupun pencahayaan. Museum Modern and Contemporary Art in Nusantara berada di Jakarta yang merupakan ibukota Indonesia. Dengan mengangkat tema Global Metropolitan Culture, yaitu pengangkatan budaya metropolitan yang diharapkan dapat mendunia dengan menerapkan gaya kontemporer. Citra dari museum yang ingin ditampilkan yaitu menyenangkan, nyaman, bersih dan dengan memadukan konsep edukasi yang modern sehingga museum akan menggunakan fasilitas yang modern sebagai sarana pemberi edukasi kepada pengunjung agar informasi tentang koleksi yang dipamerkan oleh museum dapat diterima dengan baik dan diharapkan dapat memberikan wawasan untuk pengunjung.
\end{abstract}

Kata kunci: interior; museum; contemporar; seni; pengunjung

\section{ABSTRACT}

Amid modernization like today the existence of museums has begun to be neglected. With the existence of the Modern Museum and Contemporary Art in Nusantara, which is a Jakarta-based art institution that became the first in its kind. This museum is the first to provide public access to a collection of modern and contemporary art from Indonesia and internationally. Has an active program of exhibitions and events in facilities covering an area of 7,100 square meters including education in conservation areas and spaces. The museum is an institution that remains for the benefit of the community and its development and is open to the public with educational and recreational purposes. So from that the design of a museum interior needs to be considered in order to support the success of a museum design, among others in terms of display techniques, gallery categorization, signage systems, and lighting. The Modern and Contemporary Art in Nusantara Museum is located in Jakarta which is the capital of Indonesia. By raising the theme of Global Metropolitan Culture, namely the appointment of metropolitan culture that is expected to be global by applying contemporary styles. The image of the museum that wants to be displayed is fun, comfortable, clean and by combining modern educational concepts so that the museum will use modern facilities as a means of providing education to visitors so that information about the collections exhibited by the museum can be well received and is expected to provide insight for the visitor.

Keyword: interior; museum; contemporary; art; visitors

\section{PENDAHULUAN}

Ditengah modernisasi seperti dewasa ini keberadaan museum mulai terabaikan. Kebanyakan masyarakat tidak tertarik lagi untuk berekreasi maupun mencari pengetahuan 
dengan pergi ke museum, karena adanya Mall, area rekreasi atau sarana hiburan lainnyaTidak sedikit yang menganggap museum identik dengan tempat yang kuno, seram dan tidak menarik untuk dikunjungi. Banyak orang salah paham bahwa museum adalah tempat menaruh barangbarang kuno, berdebu, dan hanya diminati kalangan tua. Objek wisata yang berupa Museum akan selalu sepi dari objek wisata lainnya. Saat ini tempat wisata, seperti rumah makan, waterboom, agro wisata lebih menarik daripada museum yang sebenarnya menyimpan ilmu yang tidak ternilai. Museum sudah tidak menarik dengan kemasan yang statis, dari mulai berdirinya hingga kurun waktu yang lama. Dengan dasar seperti itu masyarakat merasa bosan untuk datang ke museum. Padahal dewasa ini masyarakat selalu saja mencari sesuatu yang baru sebagai pengobat kejenuhan sehari-hari. Kalau hanya mendatangi museum, dengan objek yang tidak pernah berubah, mereka tidak akan mendapatkan apa-apa. Kecuali mereka yang sedang mengadakan penelitian tentang benda bersejarah. Itupun hanya akan mendapatkan data kasar, sebab mereka tidak bisa melakukan penelitian secara detail, disebabkan fasilitas di museum untuk melakukan penelitian tidak memadai, bahkan bisa dikatakan tidak ada. Penjaga museum hanya mempunyai perspektif konservasi dan preservasi. Mereka hanya berhenti pada konservasi, tetapi jangan disentuh, jangan difoto dan sebagainya. Aspek edukasi sangat nihil. Dan yang keempat, museum belum menjadi wahana pembelajaran kecintaan terhadap bangsa.

Museum Modern and Contemporary Art in Nusantara merupakan institusi seni berbasis di Jakarta yang menjadi pertama dalam jenisnya. Museum ini adalah yang pertama untuk memberikan akses publik terhadap koleksi seni modern dan kontemporer yang berasal dari Indonesia dan internasional. Memiliki program pameran dan acara aktif di fasilitas seluas 7.100 meter persegi termasuk pendidikan di tempat dan ruang konservasi juga berkomitmen untuk membuat seni lebih mudah diakses publik luas, dan menjadikan edukasi sebagai jantung dari program- programnya. Salah satunya adalah dengan disediakannya Children's Art Space yang dapat menjadikan seni lebih mudah dimengerti dan dihargai oleh anak-anak dari usia dini. Museum ini menampilkan sekitar 90 karya dari koleksi total 800 karya seni Indonesia dan kontemporer modern dari seluruh dunia termasuk 'Infinity Mirrored Room' oleh seniman Jepang Yayoi Kusama. Seni kontemporer dan modern yang ditampilkan oleh Museum Modern and Contemporary Art in Nusantara tidak terbatas pada lukisan, tetapi juga mencakup gaya kontemporer menggunakan berbagai media, teknik, dan seni instalasi.

\section{METODE PENELITIAN}

Metode yang digunakan dalam penelitian ini sebagai berikut:

\section{A. Data Literatur}

Tahap awal dalam Perancangan Desain Interior Museum Modern and Contemporary Art in Nusantara ini adalah mengumpulkan data-data literatur dan sumber-sumber referensi desain yang akan dicapai. Penulis mengumpulkan data-data yang berhubungan Perancangan Desain Interior Museum Modern and Contemporary Art in Nusantara, data yang dikumpulkan berupa standard perancangan museum dan public space, serta aspek-aspek lain yang mendukung perancangan museum ini.

\section{B. Data Lapangan Fisik dan Non Fisik}

Penulis melakukan survey lokasi yang akan dirancang sebagai museum dan mengumpulkan data-data fisik maupun nonfisik dari bangunan tersebut. Data nonfisik yang didapat berupa data proyek, standarisasi museum dan keinginan klien. Sedangkan data fisik yang diperoleh berupa lokasi, bentuk dan luas bangunan serta denah dan ukuran. Lokasi yang dipilih terletak di kota Jakarta dan lokasi yang digunakan harus strategis, memiliki akses yang mudah dan berada dalam daerah komersil yang sedang berkembang. 
Vol. 4, No. 2, Desember 2019, pISSN 2527-2853, eISSN 2549-2985

\section{Daftar Kebutuhan}

Daftar untuk memenuhi kebutuhan ruang, berisi daftar fungsi dan aktivitas ruang serta daftar kebutuhan furnitur dalam ruangan tersebut.

\section{Permasalahan Desain}

Permasalahan bisa berasal dari data existing, data lapangan serta visi misi dan keinginan klien, namun dalam kasus kali ini keinginan klien sekaligus menjadi permasalahan desain.

\section{E. Konsep Desain}

Setelah mengumpulkan data, menemukan dan memecahkan permasalahan, perancang akan memulai menentukan konsep yang ingin diwujudkan dalam Perancangan Desain Interior Museum Modern and Contemporary Art in Nusantara ini. Konsep dalam desain interior adalah sebuah dasar pemikiran desainer dalam memecahkan permasalahan desain. Konsep juga digunakan sebagai acuan desain agar perancangan memiliki batasan desain sehingga saat merancang, desain tidak terlalu meluas dan keluar jalur. Konsep akan membentuk batasan desain, suasana, bentukan, sirkulasi dan perilaku pengguna yang ingin dibentuk dan diharapkan oleh perancang dalam desainnya. Dalam perancangan hotel ini konsep yang digunakan adalah Global Metropolitan Culture, yaitu pengangkatan budaya metropolitan yang diharapkan dapat mendunia dengan menerapkan gaya kontemporer. Di daerah Jakarta yang merupakan sebuah pusat populasi besar yang terdiri atas satu metropolis besar dan daerah sekitarnya, atau beberapa kota sentral yang saling bertetangga dan daerah sekitarnya. Dengan menerapkan gaya kontemporer pada ruangannya.

\section{F. Solusi Alternatif}

Adalah proses setelah konsep desain, dimana biasanya konsep yang sudah kita buat dari ide-ide diberi alternatif desain untuk dipertimbangkan kepada klien yang nantinya akan dipilih sesuai dengan pendekatan dengan kriteria desain yang sudah ada.

\section{G. Kriteria Desain}

Tahap ini adalah acuan desain yang akan dibentuk, seperti suasana ruang, penghawaan, pencahayaan, material dan ambience yang akan dibentuk dalam ruangan tersebut. Sehingga memudahkan perancang dalam tahap pemilihan solusi alternatif dari ide-ide konsep desain.

\section{H. Final Desain}

Tahap ini adalah tahap terakhir dari proses desain dengan pertimbangan solusi alternatif yang sudah dibuat dan mempertimbangkan kriteria desain serta diperkuat dengan konsep gaya dan tema.

\section{HASIL PENELITIAN DAN PEMBAHASAN}

\section{A. Konsep dan Perancangan}

Konsep pada perancangan Museum Modern and Contemporary Art in Nusantara adalah Global Metropolitan Culture, yaitu pengangkatan budaya metropolitan yang diharapkan dapat mendunia dengan menerapkan gaya kontemporer. Di daerah Jakarta yang merupakan sebuah pusat populasi besar yang terdiri atas satu metropolis besar dan daerah sekitarnya, atau beberapa kota sentral yang saling bertetangga dan daerah sekitarnya. Metropolitan merupakan sebuah sistem perkotaan yang berarti kumpulan kota-kota yang saling berinteraksi dan bekerja sama untuk mencapai tujuan tertentu dalam lingkungan yang kompleks. Citra dari museum yang 
ingin ditampilkan yaitu menyenangkan, nyaman, tenang, bersih dan dengan memadukan konsep edukasi yang modern sehingga museum akan menggunakan fasilitas yang modern sebagai sarana pemberi edukasi kepada pengunjung agar informasi tentang koleksi yang dipamerkan oleh museum dapat diterima dengan baik dan diharapkan dapat memberikan wawasan untuk pengunjung. Area perancangan Museum Modern and Contemporary Art in Nusantara meliputi area ruang pameran.

\section{Penggunaan Material}

Dinding: Material yang diterapkan pada perancangan interior Museum Modern and Contemporary Art in Nusantara dominan menggunakan material sebagian besar dari alam.

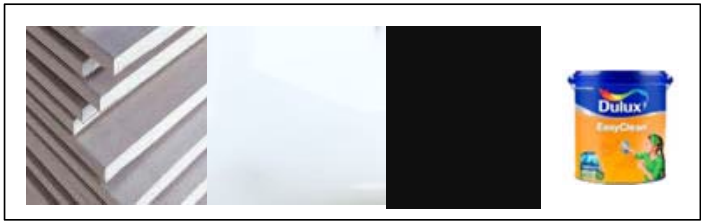

Gambar 1. Gypsum Board, HPL Putih, HPL Hitam dan Cat Tembok Dulux Sumber: Diolah dari Berbagai Sumber (2019)

Lantai: Material lantai yang digunakan pada setiap ruang berbeda-beda sesuai dengan aktifitas dan suasana ruang yang ingin diterapkan pada setiap ruangan. Pemilihan material pada perancangan interior merupakan salah satu hal yang harus diperhatikan. Penggunaan homogenouse tile untuk area yang sering dilewati orang banyak dan penggunaan lantai parket solid di dalam area pameran. Penggunaan lantai dengan material karpet diterapkan pada ruang rapat, kepala museum, staff dan mini theater sebagai peredam suara langkah kaki agar tidak mengganggu di dalam ruangan. Berikut adalah material lantai yang akan digunakan.

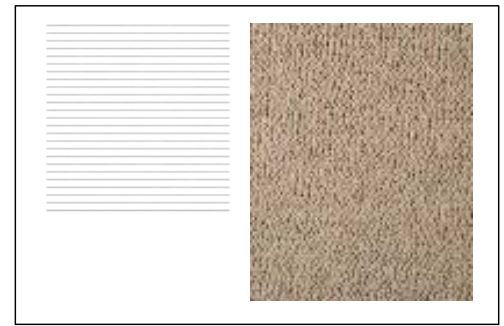

Gambar 2. Acian Finishing Epoxy Glossy dan Wool Carpet Sumber: Diolah dari Berbagai Sumber (2019)

Plafon: Material yang akan digunakan pada plafon adalah material gypsum yang akan digunakan hampir disemua ruangan. Pada area pameran menggunakan plafon gypsum.

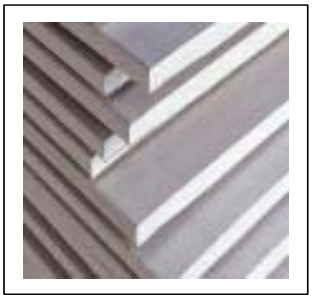

Gambar 3. Gypsum Board

Sumber: Diolah dari Berbagai Sumber (2019) 
Pencahayaan: Terdapat 2 jenis Pencahayaan yang diterapkan yaitu cahaya matahari (alami) dan cahaya lampu (buatan). Cahaya matahari banyak digunakan ketika siang hari. Namun untuk menjaga ruangan agar tetap terang juga menerangi area yang tidak terkena matahari ditambahkan cahaya dari lampu. Terdapat berbagai jenis lampu yang digunakan yaitu spotlight, LED Strip dan hidden lamp.

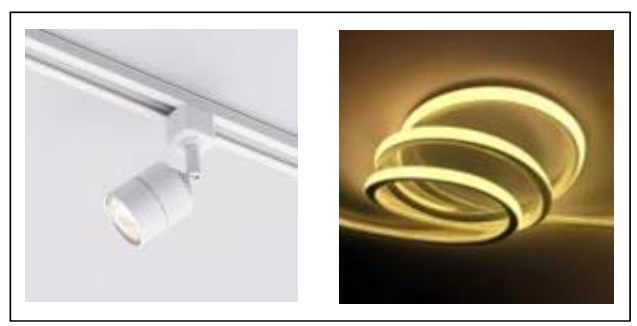

Gambar 4. Spotlight dan LED Strip

Sumber: Diolah Dari Berbagai Sumber (2019)

\section{Penghawaan}

Penghawaan merupakan aspek teknis utama yang perlu diperhatikan untuk mengatur sirkulasi udara. Pada museum dengan koleksi utama kelembaban yang disarankan adalah $50 \%$ dengan suhu $21^{\circ} \mathrm{C}-26^{\circ} \mathrm{C}$. Sistem penghawaan buatan di dalam museum menggunakan Air Conditioner (AC) untuk penghawaan central dan exhaust fan untuk mengatur sirkulasi udara, dan humidifier untuk mengendalikan kelembaban dalam ruangan (Naufert Ernst, 2002).

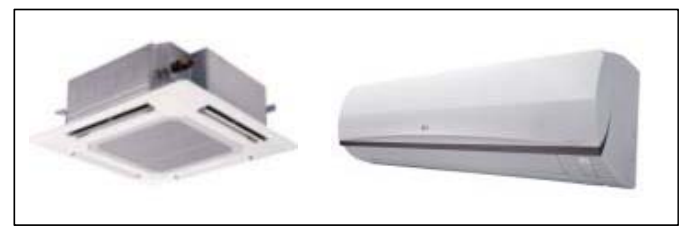

Gambar 5. AC Central dan AC Split

Sumber: Diolah dari Berbagai Sumber (2019)

\section{Keamanan dan Keselamatan (Utilitas)}

Konsep keamanan dan keselamatan di dalam museum. Untuk meminimalisir kejadian seperti pencurian dan perusakan terhadap benda koleksi maka museum menggunakan sistem keamanan di dalam maupun di luar museum. Dan untuk keselamatan di dalam museum juga harus diperhatikan untuk keselamatan pengunjung maupun pengelola yang ada di dalam museum. Berikut adalah konsep utilitas bangunan yang akan di terapkan.

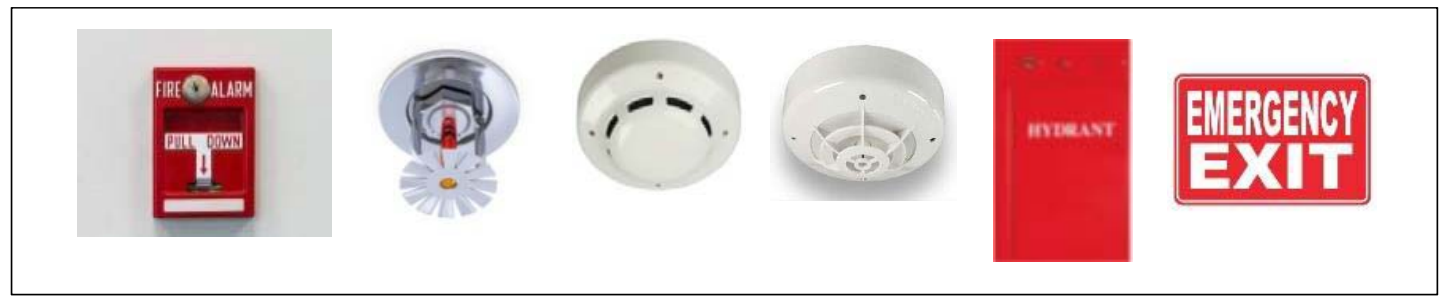

Gambar 6. Sprinkle Water, Smoke Detectore, Heat Detector, Fire Detector, Hydrant, Dan Emergency Exit Sumber: Diolah dari Berbagai Sumber (2019) 


\section{B. Hasil Perancangan Interior}

1. Lay Out

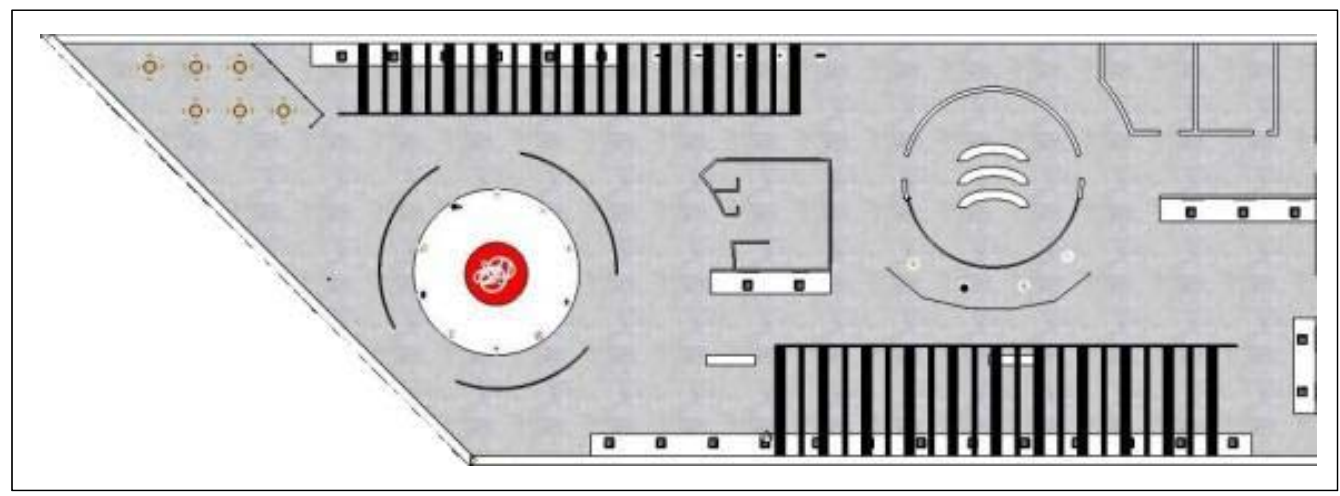

Gambar 7. Layout Keseluruhan Sumber: Data Pribadi (2019)

2. Perspektif Ruang Pameran 1

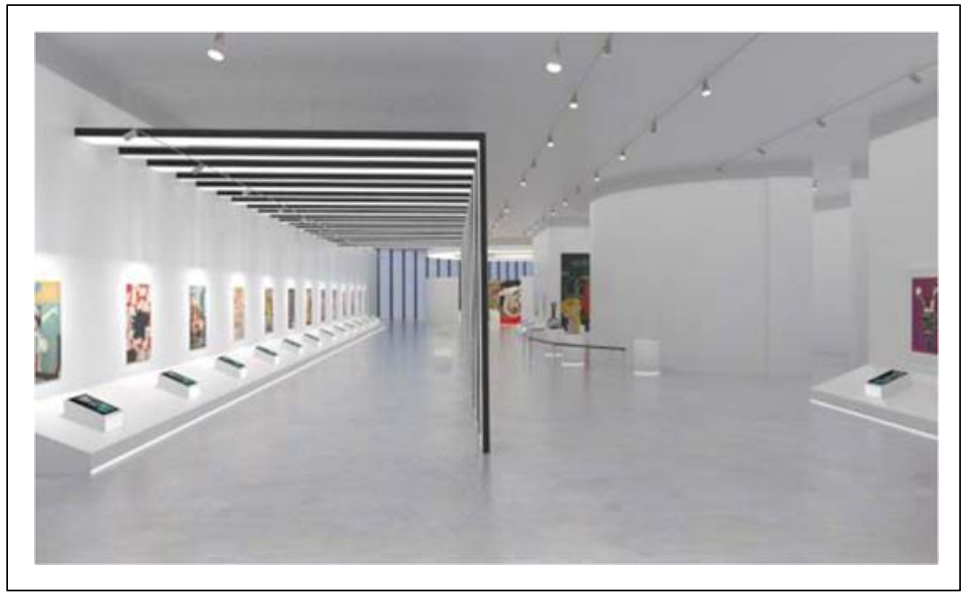

Gambar 9. Perspektif Ruang Pameran 1 View 1 Sumber: Data Pribadi (2019)

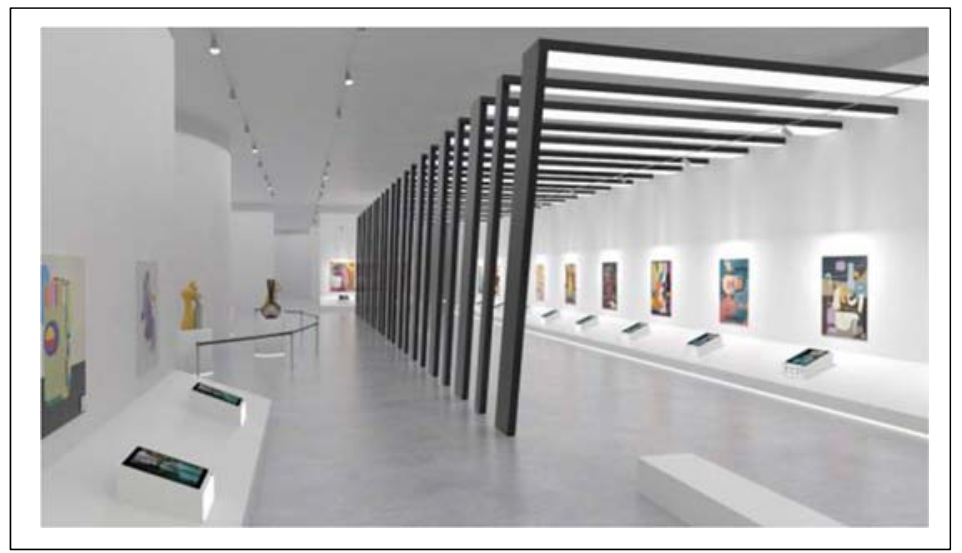

Gambar 10. Perspektif Ruang Pameran 1 View 2 Sumber: Data Pribadi (2019) 
3. Tampak Ruang Pameran 2

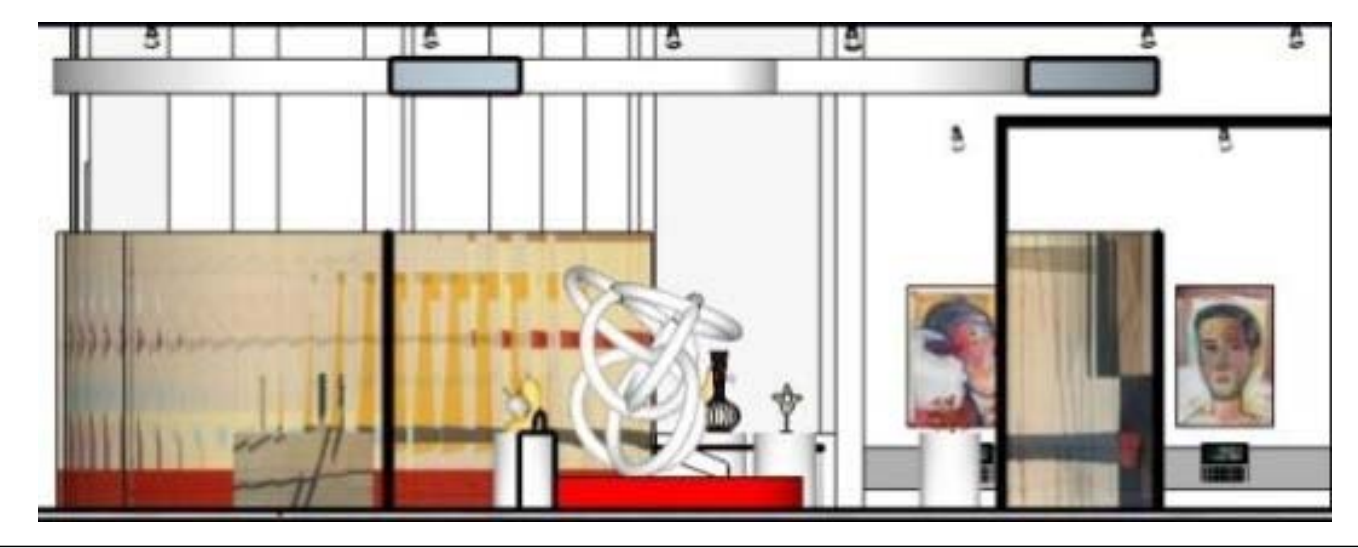

Gambar 11. Tampak Ruang Pameran 2 Sumber: Data Pribadi (2019)

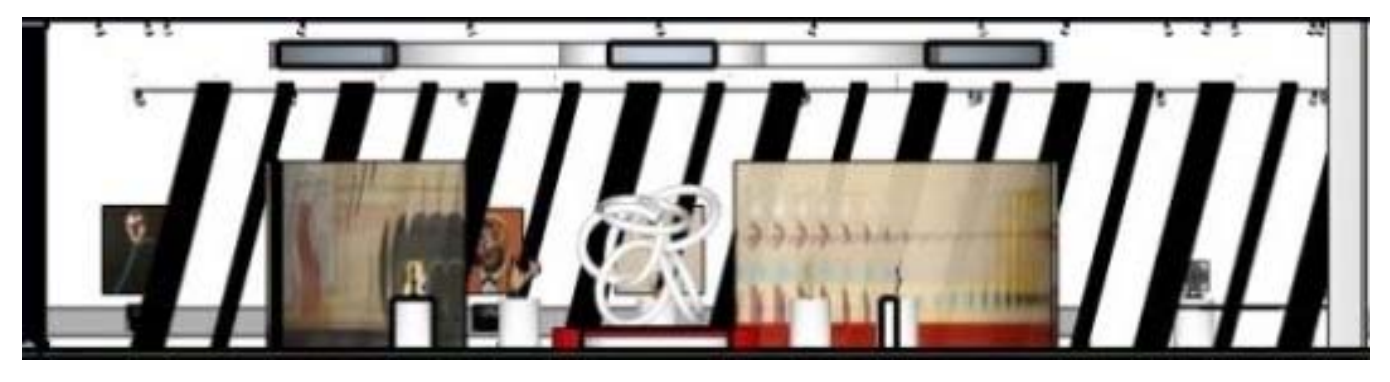

Gambar 12. Tampak Ruang Pameran 2 Sumber: Data Pribadi (2019)

4. Perspektif Ruang Pameran 2

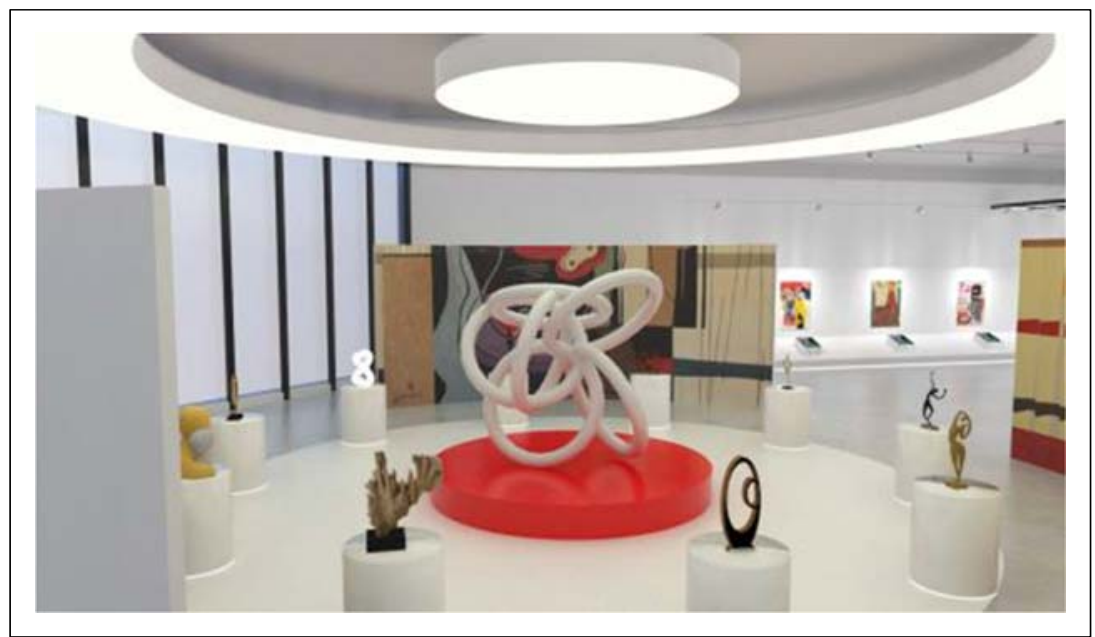

Gambar 13. Ruang Pameran 2 View 1 Sumber: Data Pribadi (2019) 
Tunjung Atmadi, Kiki Nurmallah

Desain Interior Museum Modern and Contemporary Art in Nusantara, Konsep Global Metropolitan Culture

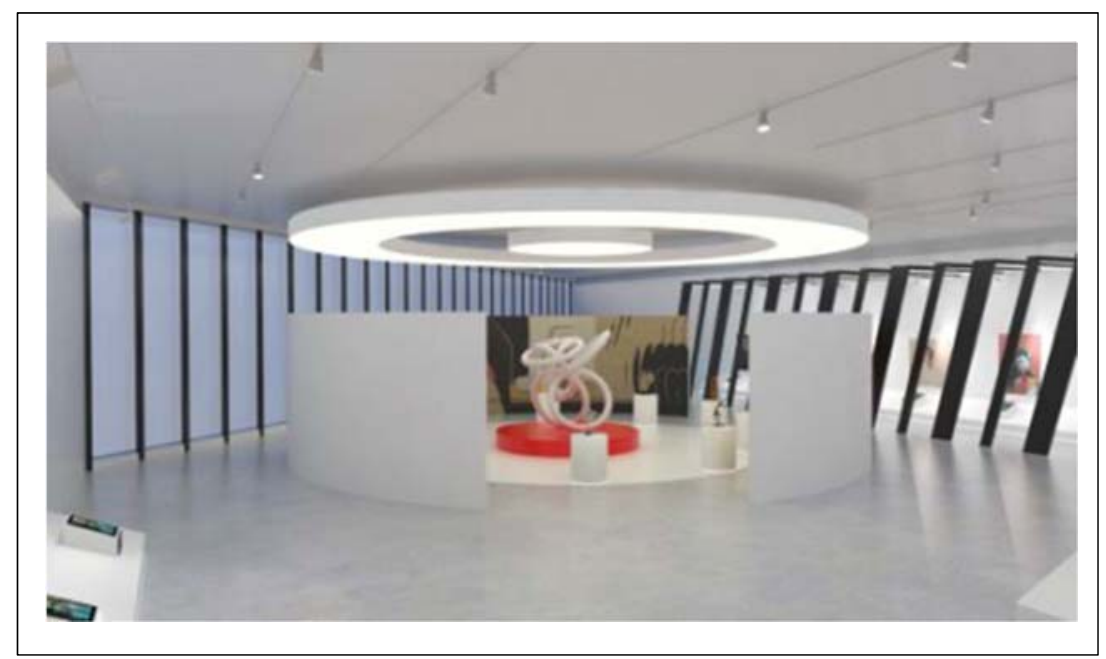

Gambar 14. Ruang Pameran 2 View 2

Sumber: Data Pribadi (2019)

5. Tampak Ruang Pameran 3

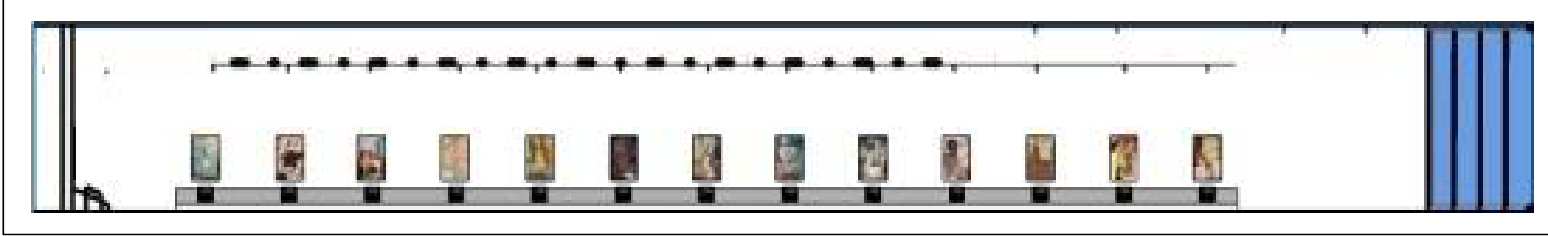

Gambar 15. Tampak Ruang Pameran 3

Sumber: Data Pribadi (2019)

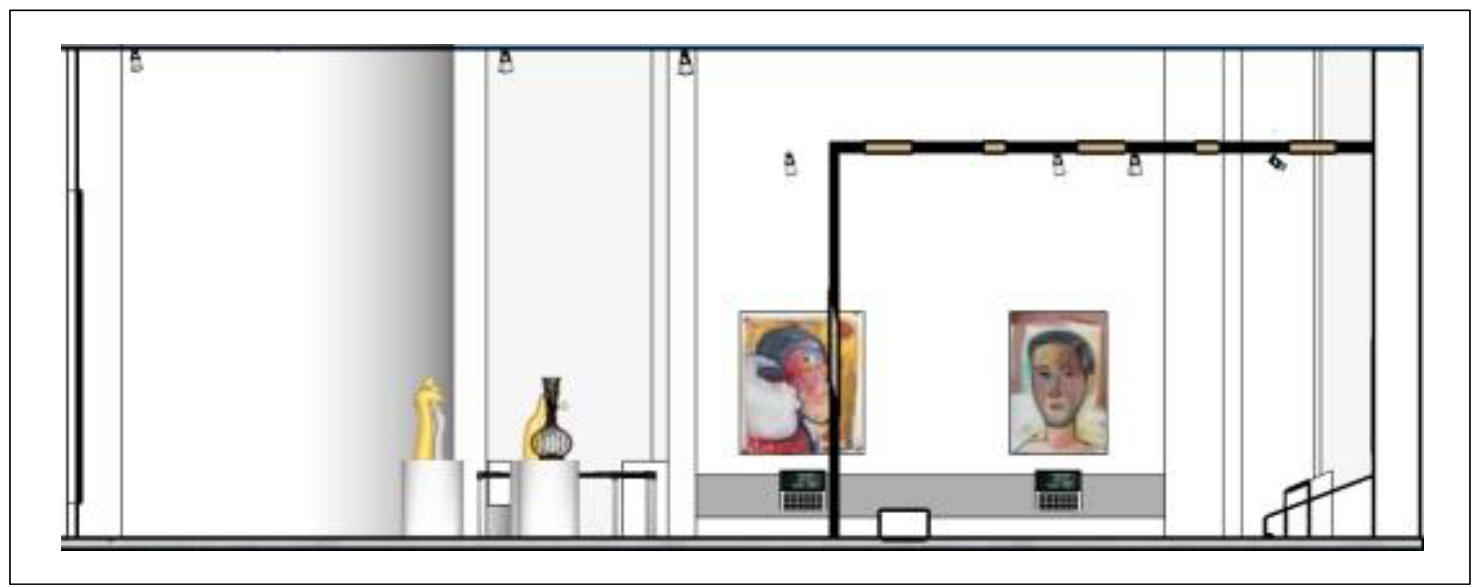

Gambar 16. Ruang Pameran 3 View 1

Sumber: Data Pribadi (2019) 
6. Perspektif Ruang Pameran 3

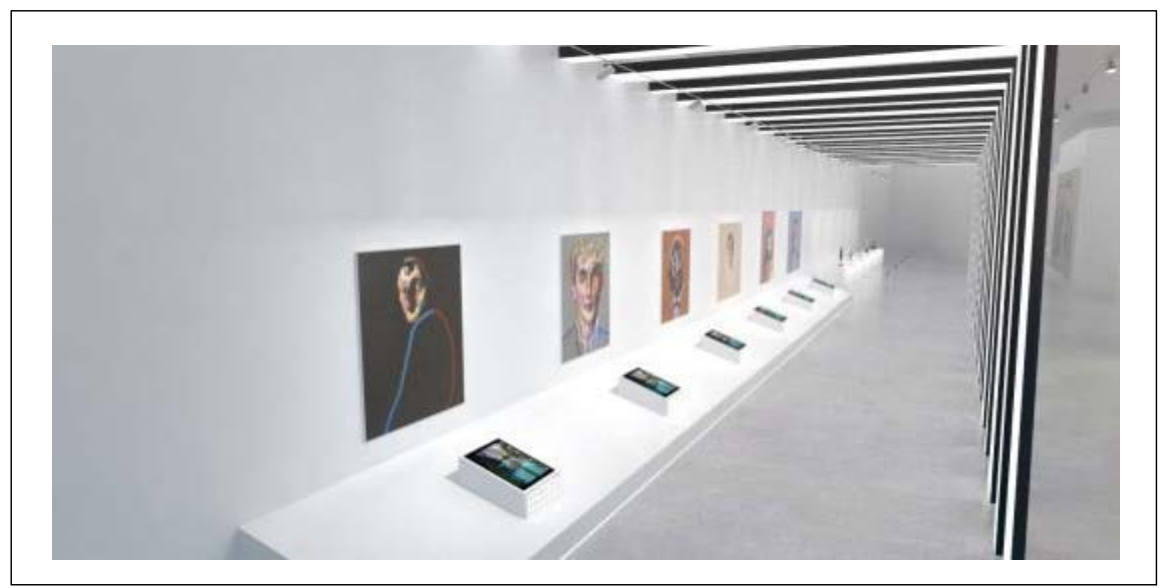

Gambar 17. Ruang Pameran 3 View 2

Sumber: Data Pribadi (2019)

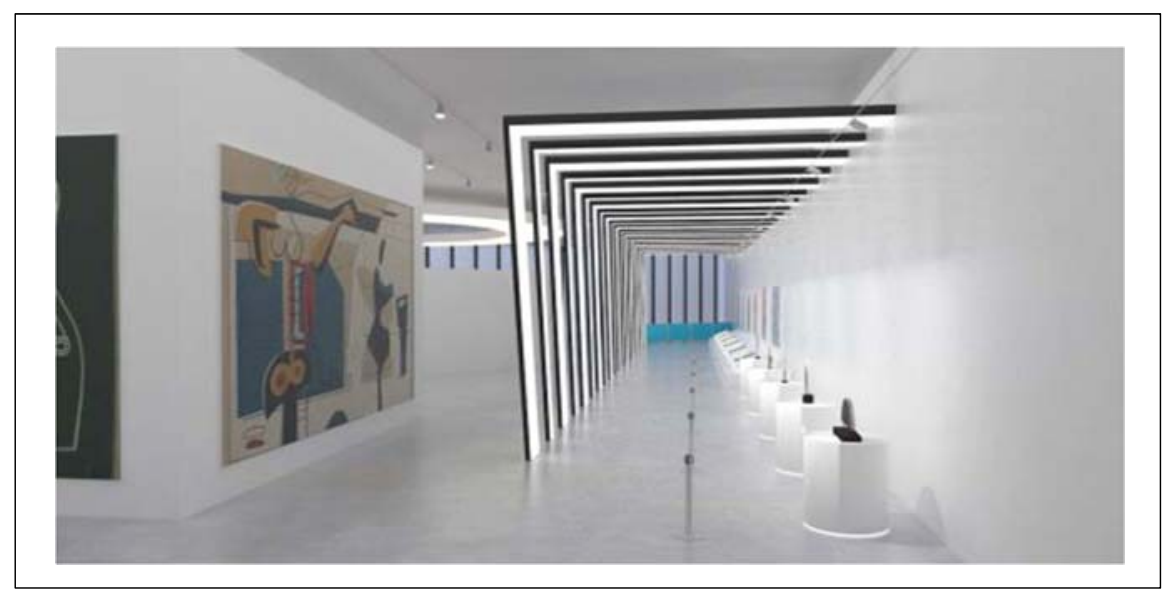

Gambar 18. Ruang Pameran 3 View 2

Sumber: Data Pribadi (2019)

\section{KESIMPULAN}

Kebanyakan masyarakat tidak tertarik lagi untuk berekreasi maupun mencari pengetahuan dengan pergi ke museum, karena adanya Mall, area rekreasi atau sarana hiburan lainnya. Tidak sedikit yang menganggap museum identik dengan tempat yang kuno, seram dan tidak menarik untuk dikunjungi. Banyak orang salah paham bahwa museum adalah tempat menaruh barangbarang kuno, berdebu, dan hanya diminati kalangan tua. Museum sebenarnya menjadi tempat pembelajaran dan mencari ilmu yang baik karena dapat memberikan wawasan yang luas, dan juga menjadi sarana rekreasi serta menambah inspirasi.

Museum Modern and Contemporary Art in Nusantara dirancang sebagai institusi yang memberikan akses terhadap koleksi seni modern dan kontemporer yang signifikan dan terus berkembang dari Indonesia dan seluruh dunia. Museum ini memiliki program pameran dan acara aktif yang mencakup ruang pendidikan dan konservasi. 
Dengan menerapkan tema Global Metropolitan Culture dalam desain interior. Museum Modern and Contemporary Art in Nusantara dapat memberikan sebuah pembelajaran dengan visualisasi yang menarik mengenai seni kontemporer baik yang ada di Indonesia maupun di seluruh dunia sehingga masyarakat menjadi lebih memahami informasi tentang koleksi benda museum yang dipamerkan.

\section{DAFTAR PUSTAKA}

Agus, S. (1998). Pedoman Tata Pameran di Museum. Jakarta: Proyek Pembinaan Permuseuman Jakarta.

Atmadi, T. (2018). Revitalisasi Desain Interior Museum Kebangkitan Nasional dan Museum Sumpah Pemuda Jakarta. Jurnal Narada. Vol. 5 No. 3 Edisi Desember.

Direktorat Museum. (2007). Pengelolaan Koleksi Museum. Jakarta: Direktorat Museum, Direktorat Jendral Sejarah dan Purbakala, Departemen Kebudayaan dan Pariwisata.

Direktorat Museum. (2008). Pedoman Museum Indonesia. Jakarta: Direktorat Museum, Direktorat Jenderal Sejarah dan Purbakala, Departemen Kebudayaan dan Pariwisata.

ICOM (International Council of Museum). (2013). ICOM Code of Ethics for Museums. Paris: International Council of Museums.

Jonathan, Tandean. (2016). Museum Seni Kontemporer di Yogyakarta. Skripsi. Program Studi Arsitektur, Universitas Atma Jaya Yogyakarta.

Joseph De Chiara, Julius Panero, dan Martin Zelnik. (2001). Time Saver Standards for Building. New York: McGraw-Hill, Inc

Neufert, Ernst. (2002). Data Arsitek edisi 33 jilid 2, Trans Sunarto Tjahjadi dan Ferryanto Chaidir. Jakarta: Erlangga.

Permuseuman, direktorat Jendral Kebudayaan departemen Pendidikan dan Kebudayaan.

Sutaarga, Moh. Amir. (1976). Museum Di Indonesia. Jakarta: Proyek Pembinaan Permuseuman, Direktorat Jendral Kebudayaan departemen Pendidikan dan Kebudayaan.

Sutaarga, Moh. Amir. (1976). Permasalahan Museum di Indonesia. Jakarta: Proyek Pembinaan Permuseuman, direktorat Jendral Kebudayaan Departemen Pendidikan dan Kebudayaan.

Sutaarga, Moh. Amir. (1998). Pedoman Penyelenggaraan dan Pengelolaan Museum. Jakarta: Proyek Pembinaan.

Sutrisno, Heru. (2011). Museum Seni Gerabah di Kasongan, Bantul. Skripsi. Program Studi Arsitektur, Universitas Atma Jaya Yogyakarta.

Wulandari, Wiwik Sri. (2008). Seni Grafis Yogyakarta dalam Wacana Seni Kontemporer. Skripsi. Program Studi Seni Grafis, Universitas ISI Yogyakarta.

Website:

https://www.museummacan.org/about?lan g=idculture/art/museum-MACAN-indonesia-s-

http://www.mondecor.com/about

https://serupa.id/seni-rupa-kontemporer/contemporary-art-set-to-open-1.668721

https://www.thenational.ae/arts-first-international-museum-of-

https://maubelajarapa.com/educator/art1n ewmuseum/ 